\title{
A study of reactive oxygen species in mainstream of cigarette
}

\begin{abstract}
Reactive oxygenated species (ROS) not only exist in living organisms, they also exist in our environment. Combustion process and photochemical reactions are the major source of environmental ROS, and combustion process produced ROS has been gradually gaining attention in recent years. The purpose of this study is to determine the concentrations of ROS in the mainstream smoke of cigarettes sold in the marketplace using the $\mathrm{DCFH}_{2}$ fluorescence method and to understand particulate and gaseous concentrations of ROS. This research will also discuss the relationship between ROS and nicotine, found in popular cigarette brands, as well as the effectiveness of cigarette filters to remove ROS. Results indicate that the ROS concentration of mainstream smoke is 18.64$54.81 \mathrm{nmol} \mathrm{H}_{2} \mathrm{O}_{2} / 1$ while the correlation coefficients of nicotine and tar to total ROS are 0.959 and 0.909 , respectively. Gaseous ROS concentrations are 14.32 $39.03 \mathrm{nmol} \mathrm{H}_{2} \mathrm{O}_{2} / 1$, and make up $71.21-85.99 \%$ of the total. It can be clearly seen therefore, that ROS exist mainly in the gaseous phase. Particulate ROS is dominant at $\mathrm{PM}_{2.5}\left(\mathrm{ROS}_{\mathrm{TSP}} / \operatorname{ROS}_{\mathrm{PM} 2.5}\right.$ is $\left.0.652-0.959\right)$. The experimental results involving the tobacco leaves and cigarette ash show that ROS in mainstream smoke comes from the combustion process and not from the tobacco leaves. There is no effective means of eliminating ROS from mainstream smoke, regardless of whether a cigarette filter contains active charcoal.
\end{abstract}

\author{
M. -F. Huang, W. -L. Lin, Y. -C. Ma \\ Institute of Environmental Health, National Taiwan \\ University, Taipei, Taiwan \\ Key words: Reactive oxygen species; Mainstream; \\ Cigarette; Total suspended particle; $\mathrm{PM}_{2.5}$; \\ Dichlorofluorescin; $\mathrm{DCFH}_{2}$. \\ Yee-Chung $\mathrm{Ma}$ \\ Institute of Environmental Health \\ National Taiwan University \\ 1 Jen-Ai Road, Section 1 \\ Taipei \\ Taiwan \\ Tel./Fax: +886 223938631 ext 8473/ \\ +886 223418577 \\ e-mail: ycma@ha.mc.ntu.edu.tw \\ Received for review 17 December 2003. Accepted for \\ publication 6 January 2005 \\ (c) Indoor Air (2005)
}

\section{Practical Implications}

This study showed that cigarette combustion will produce high concentration of ROS, and this high concentration of ROS in mainstream cigarette smoke probably is one major factor contributing to a high incidence of lung cancer in smokers. Environmental tobacco smoke (ETS) or second-hand smoke is a major indoor air pollutant that could potentially harm non-smokers. We will try to determine the ROS in ETS in the future.

\section{Introduction}

Reactive oxygenated species (ROS) are widely found in living organisms and in the environment. Although ROS have a special function in living things, they are also toxic to cells. For example, ROS control the use of Ca-ATPase, excessively hydrolyze lipids, interfere with the function and break down enzyme structures, obstruct ATP formation and destroy DNA (Bartold et al., 1984). Clinically, ROS are implicated in diabetes (Uzel et al., 1987), inflammatory immunization injury, autoimmune systemic disease, organizational injuries resulting from blood loss (Kilgore and Lucchesi, 1993) and cancer (Kensler and Trush, 1984; Salim, 1993). More than a hundred diseases are related to ROS (Halliwell et al., 1992). When ROS were uncovered in the environment, they were found to cause the same types of harm as they do in living organisms. The source of environmental ROS is combustion and photochemical reactions. The combustion sources include mainly exhaust from vehicles (Hung and Wang, 2001), incense burning (Kao, 2001) and cigarettes. This research focuses on the characteristics of ROS in mainstream smoke from burning cigarettes.

The products of cigarette combustion can be divided into the gaseous phase and the solid particulate phase. The stable gaseous phase of ROS, which exists in the environment, does not come directly from combustion as the half-life of fire produced ROS is very short and they are $\mathrm{O}_{2}$ reacted with carbon-centric free base compounds and species; this is a product of the reaction between $\mathrm{NO}_{2}$, isoprene and other similar compounds (Church and Pryor, 1985; Pryor et al., 1983). Particles (mainly tar), when compared with stable ROS, come from free base reactions, which along with the free base half-life of semiquinone, can all be detected using electron spin resonance spectroscopy (ESR) and filter paper, and are measured using organic solvent extracts or aqueous extracts. Aqueous extracts of cigarette $\operatorname{tar}(\mathrm{ACT})$ have a low 
molecular weight quinone-hydroquinone-semiquinone system. These semiquinones release oxygen to produce ROS such as super oxide ions $\left(\mathrm{O}_{2}^{-}\right)$, further producing hydrogen peroxide $\left(\mathrm{H}_{2} \mathrm{O}_{2}\right)$ and hydroxy radicals $(\mathrm{OH})$ (Cosgrove et al., 1985; Pryor and Stone, 1993).

This study determines ROS concentrations and the gaseous and solid ROS distribution in several leading cigarette brands available in the local market. We calculated the relationship between nicotine and ROS, and measured ROS concentrations in tobacco leaves and tar, to verify whether ROS are produced by the combustion of these cigarettes. Based on the results, we further investigated the reasons for the changes in the ROS concentrations. Finally, we evaluated whether the cigarette filters of these brands can effectively reduce their ROS emissions.

\section{Method}

\section{ROS measurement}

The dichlorofluorescin fluorescence method that this study uses to determine ROS is widely employed in the measurement of ROS in biological systems. In recent years, this method has been used to determine airborne ROS in gas and particles (Cosgrove et al., 1985; Kao, 2001). $\mathrm{DCFH}_{2}$ is oxidized by ROS, creating dichlorofluorescin (DCF), which allows for a fast determination of active oxidant concentrations in a medium. As ROS include a variety of reactive chemicals, it is difficult to establish a calibration curve for each chemical. Therefore the calibration curve obtained from the reaction between $\mathrm{DCFH}_{2}$-horseradish peroxidase (HRP) and $\mathrm{H}_{2} \mathrm{O}_{2}$ was used to convert the fluorescence intensity reading for ROS to an equivalent $\mathrm{H}_{2} \mathrm{O}_{2}$ concentration. The equivalent $\mathrm{H}_{2} \mathrm{O}_{2}$ concentration is an indicator for the reactivity of the ROS in a sample that had a fluorescence intensity identical to the $\mathrm{H}_{2} \mathrm{O}_{2}$ solution of the calculated concentration. The calculation equation is show below:

$$
\begin{aligned}
& \operatorname{ROS}_{\mathrm{L}}=\frac{C \times V \mathrm{e}}{V \mathrm{~s}} \times 10^{3} \\
& \operatorname{ROS}_{\mathrm{mg}}=\frac{C \times V \mathrm{e}}{W} \times 10^{3}
\end{aligned}
$$

Where $\operatorname{ROS}_{\mathrm{L}}$ is concentration of ROS in particle phase $\left(\mathrm{PM}_{2.5}\right.$ and TSP) and gas phase, the unit is nmol $\mathrm{H}_{2} \mathrm{O}_{2}$ / 1 of air. $\mathrm{ROS}_{\mathrm{mg}}$ is concentration of ROS in particle phase, the unit is nmol $\mathrm{H}_{2} \mathrm{O}_{2} / \mathrm{mg}$ of particle. $C$ is ROS concentration in $\mathrm{DCFH}_{2}$-HRP solution, the unit is $\mu \mathrm{M}$. $V \mathrm{e}$ is volume of $\mathrm{DCFH}_{2}-\mathrm{HRP}$ solution, unit is litter. $V \mathrm{~s}$ is sampling volume of mainstream smoke, the unit is litter. $W$ is particle mass in a sample, the unit is milligram.

$\mathrm{DCFH}_{2}$ reagent was manufactured by mixing DA-DCFH $_{2}$ (Molecular Probes, Eugene, OR, USA) into anhydrous alcohol to make a $1 \mathrm{~mm}$ reserve solution. A $0.5 \mathrm{ml}$ solution was extracted and mixed with $2 \mathrm{ml}$ $(0.01 \mathrm{~N}) \mathrm{NaOH}$. It was kept in the shade at room temperature for $30 \mathrm{~min}$ so that it could form $\mathrm{DCFH}_{2}$ in the alkaline environment. A $10 \mathrm{ml} 25 \mathrm{~mm}$ phosphate buffer solution was mixed ( $\mathrm{pH}=7.2)$ and kept in a cool shaded place. Before analysis, HRP (Sigma Chemical, St. Louis, MO, USA) was used to make the concentration 2.2 units $\mathrm{HRP} / \mathrm{ml}$. This was used to catalyze the reaction of $\mathrm{DCFH}_{2}$ and ROS. A sample was then taken from the $\mathrm{DCFH}_{2}-\mathrm{HRP}$ mixture.

\section{Preparation of standard curve and $\mathrm{QA} / \mathrm{OC}$}

$\mathrm{H}_{2} \mathrm{O}_{2}$ solutions with five different concentrations were extracted, $0.1 \mathrm{ml}$ each, and mixed with $3 \mathrm{ml} \mathrm{\textrm {DCFH } _ { 2 } -}$ HRP reagent to make different concentrations from $0.01-0.3 \mu \mathrm{M} ; 0.1 \mathrm{ml}$ of deionized water and $3 \mathrm{ml}$ of $\mathrm{DCFH}_{2}$-HRP reagent were mixed to form the reagent blank. After being kept at $37^{\circ} \mathrm{C}$ for $15 \mathrm{~min}$, they were moved to room temperature for another $5 \mathrm{~min}$, and then $0.1 \mathrm{ml}$ was distributed onto a 96 Microtiter Well Plate. The fluorescence intensity was measured using a Cytofluor 2300 microplate reader (excitation wavelength of $485 \mathrm{~nm}$ and emission wavelength of $530 \mathrm{~nm}$, Millipore, Billerica, MA, USA). The standard curve equation is $\left[\mathrm{H}_{2} \mathrm{O}_{2}\right]=0.257(\mathrm{FI})-77.39, R^{2}=0.9992$, see Figure 1. The detection limit of this research method is $5.8 \times 10^{-3} \mu \mathrm{M} \mathrm{H}_{2} \mathrm{O}_{2}$. The average recovery efficiency is $91.91-137.46 \%$. Both the reagent blank and the field blank were each determined, so that the background value could be subtracted. Triplicate analysis was done on all samples and the results were presented as an average \pm standard deviation.

\section{Gaseous and particulate ROS sampling methods}

A three-part holder was mounted in front of four serially connected impingers (SKC, Eighty Four, Pennsylvania, USA, Midget Impinger, 36835, graduated, fritted inlet tube). Polycarbonate filters of $37 \mathrm{~mm}$ were inserted into the filter holder to collect ROS in the total suspended particle (TSP) of the mainstream

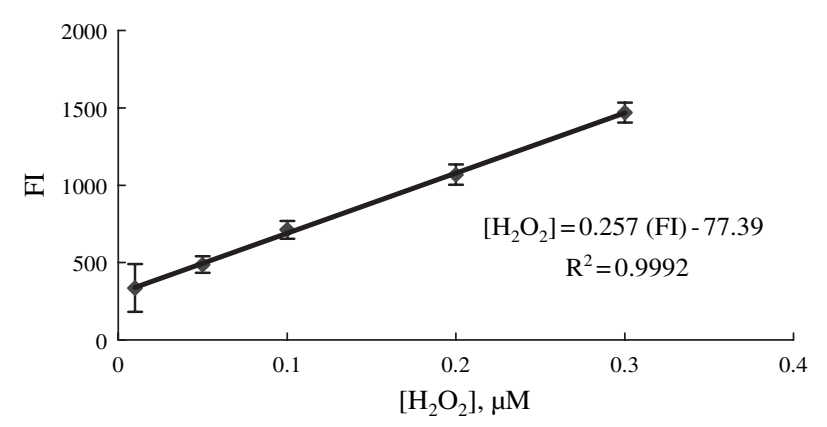

Fig. 1 The standard curve obtained by reaction of $\mathrm{DCFH}_{2}$ HRP with $\mathrm{H}_{2} \mathrm{O}_{2}$ solutions 
smoke. The $25 \mathrm{ml}$ impingers, which contained $15 \mathrm{ml}$ $\mathrm{DCFH}_{2}-\mathrm{HRP}$ reagents, collected the gaseous ROS of the mainstream smoke at a sampling flow rate of $0.5 \mathrm{l} /$ min and sampling duration of $1 \mathrm{~min}$. To calculate the particulate mass concentration, the filter papers were weighed before and after sampling. Furthermore, a PEM PM 2.5 sampler (Personal Environmental Monitor $\mathrm{PM}_{2.5}$, SKC, Eighty Four, Pennsylvania, USA) was used to sample $\mathrm{PM}_{2.5}$ and then used to analyze the ROS concentration in $\mathrm{PM}_{2.5}$. The sampling flow rate was $4 \mathrm{l} / \mathrm{min}$ and sampling duration was $1 \mathrm{~min}$.

\section{Sample analysis}

After sampling, the reagents were extracted from the impingers, pulled into the amber vials and then set at $37^{\circ} \mathrm{C}$ for $15 \mathrm{~min}$. The mixture of $10 \mathrm{ml} \mathrm{DCFH} \mathrm{D}_{2}-\mathrm{HRP}$ and TSP samples were sonicated for $10 \mathrm{~min}$; this was repeated thrice. The three exacts were mixed and then incubated at $37^{\circ} \mathrm{C}$ for $15 \mathrm{~min}$. The fluorescence intensity was read from $100 \mu$ of the above solution by the Cytofluor 2300 microplate reader (Millipore, Billerica, $\mathrm{MA}$, USA) and presented in the form of $\mathrm{H}_{2} \mathrm{O}_{2}$ concentration.

Relationship between nicotine and ROS generated by cigarette combustion

The cigarette brands used in this research are the three best-selling brands in Taiwan. The correlation between nicotine and ROS was investigated by experiments on three brands of cigarettes with different nicotine content. Brand A, a light cigarette, has a lower nicotine and tar content. The amounts of tar and nicotine are 0.5 and $5 \mathrm{mg}$, respectively; tobacco leaves and spices are its main components. Brand B is also composed of tobacco leaves and spices and contains tar and nicotine at 13 and $1.1 \mathrm{mg}$, respectively. Brand $\mathrm{C}$ has a tar and nicotine content of 15 and $1.4 \mathrm{mg}$, respectively, which is considered to be at the higher end of the spectrum. Its main components are Flue-Cured tobacco leaves, licorice, and spices.

\section{ROS in tobacco leaves and cigarette ash}

In order to understand whether the ROS contained in major cigarette brands is generated by combustion, the concentrations of ROS in both the tobacco leaves and the ash remaining after combustion were analyzed. The tobacco leaves and the ash were first weighed and then placed in amber vials; $10 \mathrm{ml} \mathrm{DCFH}_{2}$-HRP reagents were added to the vials. After three sessions of sonication lasting $10 \mathrm{~min}$ each, three extracts were obtained. The intensity of fluorescence in the extracts were read and analyzed by the same method as before and presented in the form of an $\mathrm{H}_{2} \mathrm{O}_{2}$ concentration. The procedure used to process the samples obtained in this section was the same as used on the TSP samples.

Effectiveness of filter in removal of ROS

To study the effectiveness of cigarette filters in the removal of ROS, we also selected, from the major cigarette brands, cigarettes manufactured with active carbon filters attached. The change in concentrations of gaseous and particulate (TSP and $\mathrm{PM}_{2.5}$ ) ROS, with and without filters, was compared.

\section{Results}

ROS contained in mainstream smoke from cigarette combustion

Total ROS concentrations in the mainstream smoke of cigarette brands $\mathrm{A}, \mathrm{B}$ and $\mathrm{C}$ were $18.64 \pm 4.57$, $41.61 \pm 5.46$, and $54.81 \pm 3.41 \mathrm{nmol}_{2} \mathrm{O}_{2} / 1$, respectively (Table 1). The correlation coefficient $(r)$ between total ROS and nicotine was 0.959 and between ROS and tar was 0.909 .

\section{ROS gas/particulate partitioning in mainstream smoke}

Table 1 lists the ROS concentrations in TSP of all brands of cigarettes tested: $\mathrm{A}, \mathrm{B}$ and $\mathrm{C}$. They range from 4.33 to $15.78 \mathrm{nmol}_{2} \mathrm{O}_{2} / 1$. The gaseous concentrations of ROS range from 14.32 to $39.03 \mathrm{nmol} \mathrm{H}_{2} \mathrm{O}_{2} /$ 1 while the percentage of TSP is $14.0-28.8 \%$. Therefore, the ROS in mainstream smoke, generated by combustion, exists mainly in gaseous form.

\section{ROS partitioning in $\mathrm{PM}_{2.5}$ and TSP}

According to the results of our experiments, shown in Table 2, the particle mass concentrations in $\mathrm{PM}_{2.5}$ and TSP in cigarette smoke were $1.23-1.75$ and $1.47-$ $2.13 \mathrm{mg} / \mathrm{l}$, respectively. The calculated $\mathrm{PM}_{2.5} / \mathrm{TSP}$ ranged from 0.750 to 0.875 . In terms of the amount of ROS per milligram of particulate, ROS concentrations in TSP for mainstream smoke among the three major cigarette brands went from 2.20 to $5.61 \mathrm{nmol}$ $\mathrm{H}_{2} \mathrm{O}_{2} / \mathrm{mg}$; ROS concentrations in $\mathrm{PM}_{2.5}$ ranged from

Table 1 The ROS concentration of gas phase and particle phase from mainstream

\begin{tabular}{|c|c|c|c|c|c|c|}
\hline & $\mathrm{TSP}\left(\mathrm{nmol} \mathrm{H} \mathrm{H}_{2} / \mathrm{l}\right)$ & Gas phase $\left(\mathrm{nmol} \mathrm{H}_{2} \mathrm{O}_{2} / \mathrm{l}\right)$ & Total ROS (nmol $\left.\mathrm{H}_{2} \mathrm{O}_{2} / \mathrm{l}\right)$ & Percentage of TSP & Nicotine (mg/cig) & $\operatorname{Tar}$ (mg/cig) \\
\hline Brand A & $4.33 \pm 1.38$ & $14.32 \pm 3.35$ & $18.64 \pm 4.57$ & 23.2 & 0.5 & 5 \\
\hline Brand B & $5.83 \pm 3.49$ & $35.78 \pm 1.96$ & $41.61 \pm 5.46$ & 14.0 & 1.1 & 13 \\
\hline Brand C & $15.78 \pm 4.70$ & $39.03 \pm 1.29$ & $54.81 \pm 3.41$ & 28.8 & 1.4 & 15 \\
\hline
\end{tabular}




\section{Huang et al.}

Table 2 The ROS concentration of TSP and $\mathrm{PM}_{2.5}$ in mainstream

\begin{tabular}{|c|c|c|c|c|c|c|}
\hline & $\mathrm{TSP}(\mathrm{mg} / \mathrm{l})$ & $\mathrm{PM}_{2.5}(\mathrm{mg} / \mathrm{l})$ & $\mathrm{PM}_{2.5} / \mathrm{TSP}$ & $\mathrm{TSP}\left(\mathrm{nmol} \mathrm{H}_{2} \mathrm{O}_{2} / \mathrm{mg}\right)$ & $\mathrm{PM}_{2.5}\left(\mathrm{nmol} \mathrm{H} \mathrm{O}_{2} / \mathrm{mg}\right)$ & $\mathrm{PM}_{2.5} / \mathrm{TSP}$ \\
\hline Brand A & $2.00 \pm 0.69$ & $1.75 \pm 0.35$ & 0.875 & $2.20 \pm 0.45$ & $2.11 \pm 0.14$ & 0.959 \\
\hline Brand B & $1.47 \pm 0.23$ & $1.23 \pm 0.28$ & 0.837 & $5.64 \pm 0.17$ & $3.68 \pm 0.53$ & 0.652 \\
\hline Brand C & $2.13 \pm 0.31$ & $1.60 \pm 0.088$ & 0.750 & $5.61 \pm 0.013$ & $5.21 \pm 0.42$ & 0.929 \\
\hline
\end{tabular}

2.11 to $5.21 \mathrm{nmol} \mathrm{H}_{2} \mathrm{O}_{2} / \mathrm{mg}$; the $\mathrm{PM}_{2.5} /$ TSP was $0.652-$ 0.959 . The results indicate that the particulate ROS in mainstream smoke is mainly $\mathrm{PM}_{2.5}$.

\section{ROS concentrations in tobacco leaves and tobacco ash}

The detected fluorescence measured in extract of tobacco leaves and tobacco ash is either extremely weak or beyond detection. It is much less than ROS concentrations in mainstream smoke generated by cigarette combustion. The results conclude that ROS contained in cigarette leaves before combustion and also in cigarette ash, are negligible. The highest ROS concentrations measured from the tobacco leaves of brands $\mathrm{A}, \mathrm{B}$ and $\mathrm{C}$ were 0.074, ND (not detectable), and $0.052 \mathrm{nmol} \mathrm{H}_{2} \mathrm{O}_{2} / \mathrm{mg}$, respectively; the highest ROS concentrations in cigarette ash were $0.55,1.14$, and $1.74 \mathrm{nmol} \mathrm{H}_{2} \mathrm{O}_{2} / \mathrm{mg}$, respectively.

\section{Effectiveness of cigarette filters}

To study whether cigarette filters are effective in absorbing or filtering ROS in mainstream smoke, research was conducted on TSP samples and gaseous ROS taken from cigarettes without filters. The results indicate that cigarette filters cannot effectively eliminate ROS in mainstream smoke. From the experimental results shown in Table 3, the total ROS concentrations in brands $\mathrm{A}, \mathrm{B}$, and $\mathrm{C}$ were $24.34 \pm 1.11$, $34.96 \pm 5.96$, and $53.18 \pm 1.86 \mathrm{nmol} \mathrm{H}_{2} \mathrm{O}_{2} / 1$, respectively, compared with the results from cigarettes with filters, where the ratios ranged from 0.76 to 1.19 (which is below the level of statistical significance). Upon further inspection of the effectiveness of eliminating

Table 3 The ROS concentration of TSP and gaseous ROS from cigarettes without filters

\begin{tabular}{lrll}
\hline & TSP $\left(\mathrm{nmol} \mathrm{H} \mathrm{H}_{2} / \mathrm{l}\right)$ & Gas phase $\left(\mathrm{nmol} \mathrm{H} \mathrm{O}_{2} / \mathrm{l}\right)$ & Total ROS (nmol H $\mathrm{O}_{2} /$ l) \\
\hline Brand A & $8.80 \pm 0.17(0.49)$ & $15.54 \pm 0.94(0.93)$ & $24.34 \pm 1.11(0.76)$ \\
Brand B & $10.44 \pm 0.61(0.56)$ & $24.52 \pm 6.56(1.47)$ & $34.96 \pm 5.96(1.19)$ \\
Brand C & $13.55 \pm 0.36(1.16)$ & $39.63 \pm 2.21(0.99)$ & $53.18 \pm 1.86(1.03)$ \\
\hline
\end{tabular}

The ratio of filter to non-filter is show in parentheses.

Table 4 The ROS concentration of TSP in mainstream compare between charcoal and non-charcoal filter cigarette $(n=3-5)$

\begin{tabular}{lll}
\hline & With filter $\left(\mathrm{nmol} \mathrm{H} \mathrm{O}_{2} / \mathrm{l}\right)$ & Without filter $\left(\mathrm{nmol} \mathrm{H}_{2} \mathrm{O}_{2} / \mathrm{l}\right)$ \\
\hline Charcoal filter & $24.51 \pm 0.27$ & $27.77 \pm 6.42$ \\
Non-charcoal filter (brand A) & $18.64 \pm 4.57$ & $24.34 \pm 1.11$ \\
\hline
\end{tabular}

ROS from mainstream smoke through filters, the results, although lower than from cigarettes without filters, were still below statistical significance (4.32$15.78 \mathrm{nmol} \mathrm{H}_{2} \mathrm{O}_{2} / 1$ with filters and $8.80-13.55 \mathrm{nmol}$ $\mathrm{H}_{2} \mathrm{O}_{2} / 1$ without filters). These ratios are between 0.49 and 1.16. The results from the experiment also indicate that gaseous ROS concentrations in mainstream smoke are not lowered significantly by filters.

In addition, experiments on cigarettes with charcoal filters were conducted. Qualitative analysis of ROS concentrations from these cigarettes was carried out and the results compared with cigarettes having similar ROS concentrations but without charcoal filters. The ROS concentrations in TSP with and without charcoal filters were $24.51 \pm 0.27$ and $27.77 \pm 6.42 \mathrm{nmol}$ $\mathrm{H}_{2} \mathrm{O}_{2} / 1$, respectively (see Table 4). As these measurements are also below statistical significance, we suggest that charcoal filters do not effectively eliminate ROS in mainstream smoke. In comparing cigarettes having similar ROS concentrations with non-charcoal filters, it was found that the addition of charcoal did not increase the effectiveness of removing ROS in TSP.

\section{Discussion}

ROS in mainstream smoke as major contributor to lung-cancer

Pryor et al. (1998) did an aqueous mainstream tar extract fractionation using a chromatography column. Speciation and animal experiments were conducted on eight fractions of 78. The results showed that fraction 2 , which had $30 \%$ of the mass of the total aqueous extracts, caused $1.5 \%$ of the damage in DNA. After verification using a gas chromatograph/mass spectrometer, the main component of fraction 2 was found to be nicotine. High concentrations of $\mathrm{H}_{2} \mathrm{O}_{2}, 1$,2-benzenediol and 1,4-benzenediol were found in fractions 5 and 6 , which had $<3 \%$ of the total mass but caused $70 \%$ of the DNA damage. $\mathrm{H}_{2} \mathrm{O}_{2}, 1,2$-benzenediol and 1, 4-benzenediol was generated by the reaction of ROS. Thus, we strongly suspect that the ROS in mainstream smoke is one of the major factors contributing to a higher incidence of lung-cancer in smokers.

ROS concentrations in mainstream smoke

The first step was to compare the ROS concentrations in mainstream smoke with the results of Kao's study of total ROS concentrations from incense (black-agalloch) combustion. In Kao's experiment, incense was 
burned in an enclosed chamber and the gaseous and particulate ROS sampled after $1 \mathrm{~h}$. Converted to $\mathrm{H}_{2} \mathrm{O}_{2}$ concentration per unit mass of particulate $(\mathrm{nmol} / \mathrm{mg})$, the ROS concentrations in $\mathrm{PM}_{1}$ and $\mathrm{PM}_{2.5}$ particulate were $11.4-13.5 \mathrm{nmol} / \mathrm{mg}$ and $10.8-15.6 \mathrm{nmol} / \mathrm{mg}$, respectively. In per unit volume, the ROS concentrations of $\mathrm{PM}_{1}$ and $\mathrm{PM}_{2.5}$ were $0.233-0.300 \mathrm{nmol} / 1$ and $0.291-0.469 \mathrm{nmol} / 1$, respectively. We speculate that the temperature of burning incense is higher, making ROS concentrations in particulate higher per unit mass. The gaseous ROS concentration was $0.94 \pm 0.06 \mathrm{nmol} / \mathrm{m}^{3}$. After mixing the incense combustion gases with $\mathrm{CO}$ (35 ppm) and NO (10 ppm), the gaseous ROS concentration dropped to zero and the ROS concentration in TSP decreased to $37 \%$. A possible reason for this result is that gaseous ROS is more reactive and easily reacts with $\mathrm{CO}$ and NO. On the other hand, particulate ROS has lower reactivity and only partially reacts with $\mathrm{CO}$ and NO. According to the results of Kao's experiment, the total ROS concentrations from incense combustion, was $1.95 \pm 0.18 \mathrm{nmol} \mathrm{H}_{2} \mathrm{O}_{2} / 1$. Calculation of the emission rate of ROS for burning incense is shown in Equation (3) below:

$$
\frac{G_{i}-Q_{\mathrm{c}} C_{t}}{G_{i}}=\exp \left(\frac{-Q_{\mathrm{c}} t}{V_{\mathrm{c}}}\right)
$$

Where, $G_{i}$ : total ROS emission rate $(\mathrm{nmol} / \mathrm{min}) ; Q_{\mathrm{c}}$ : volume of fresh air injected to the chamber $(1 / \mathrm{min}) ; C_{t}$ : ROS concentration in the chamber at time $t(\mathrm{nmol} / \mathrm{l}) ; t$ : time (min); $V_{\mathrm{c}}$ : chamber volume (1).

In Kao's experiment, $Q$ is $151 / \mathrm{min}, C_{t}$ is $1.95 \mathrm{nmol} / 1$, $t$ is $60 \mathrm{~min}, V$ is $288 \mathrm{l}$, and $G$ is calculated as $30.59 \mathrm{nmol} / \mathrm{min}$.

The ROS concentration in cigarette smoke can be calculated using Equation (4) below. The results of the three different kinds of cigarette filters (with active carbon) range from 0.32 to $27.41 \mathrm{nmol} / \mathrm{min}$.

$$
G_{\mathrm{m}}=C_{\mathrm{m}} \times Q_{s}
$$

Where, $G_{\mathrm{m}}$ : emission rate of ROS in mainstream smoke $(\mathrm{nmol} / \mathrm{min}) ; C_{\mathrm{m}}$ : total ROS concentration in mainstream smoke (nmol/l); $Q_{\mathrm{s}}$ : sampling flow rate in the mainstream smoke experiment $(1 / \mathrm{min})$.

Therefore, ROS emission rates for major cigarette brands and for incense combustion are within the same parameters. All mainstream smoke enters the lungs of the smoker. However, while it is not $100 \%$ absorbed by the smoker, the health effects are still worth investigating. This research is the first to analyze ROS concentrations in mainstream smoke using the $\mathrm{DCFH}_{2}$-HRP method.

\section{Gaseous and particulate ROS concentrations in mainstream smoke}

By partitioning the gaseous and particulate concentrations of ROS, it is clearly seen that the ROS generated by cigarette combustion exists mostly in the gaseous form. Moreover, most of the ROS from combustion have a low molecular weight and a short half-life. This inference is drawn from Pryor's research in which the ESR and spin trap methods were applied. The amount of NO in mainstream smoke is as high as $500 \mathrm{ppm}$ and this can slowly oxidize into $\mathrm{NO}_{2}$. These two gases in mainstream smoke exist mainly in the form of free radicals. One can infer that gaseous ROS are more stable adducts from the reaction between $\mathrm{NO}_{2}$ and isoprene and other similar compounds. In other words, they are carbon-centric free base compounds and species after reacting with $\mathrm{O}_{2}$ (Church and Pryor, 1985; Pryor et al., 1983).

\section{ROS concentrations in TSP and $\mathrm{PM}_{2.5}$}

In the experimental results with TSP and $\mathrm{PM}_{2.5}$, the ratios of particulate mass concentrations and ROS concentrations in particulate were found to be $\mathrm{PM}_{2.5} /$ $\mathrm{TSP}=0.750-0.875$ and $\mathrm{PM}_{2.5} / \mathrm{TSP}=0.652-0.959$, respectively. These results prove that particulate ROS in mainstream smoke generated by cigarette combustion is mainly in the form of $\mathrm{PM}_{2.5}$. Two important conclusions can be drawn: (i) a negative correlation exists between particulate size and ROS concentration; (ii) $\mathrm{PM}_{2.5}$ is easily deposited in the pulmonary alveoli; the higher the ROS concentration, the greater the harm to the respiratory tract.

The correlation between ROS and nicotine, and between ROS and tar

In correlations between ROS and nicotine, and between ROS and tar, it was noted that with increasing amounts of either nicotine or tar, the ROS concentrations released by combustion also increased, with correlation coefficients being $r=0.959$ and $r=0.909$, respectively. This agrees with the results of other researchers (Yildiz et al., 1999) regarding the correlations between the ROS generation mechanisms and either nicotine or tar. The results show a positive correlation.

The source of ROS in mainstream cigarette brands

We have proved that ROS does not exist in either unburned tobacco leaves or in cigarette ash, by the testing of extracts taken from these substances. The ROS in major cigarette brands is created, therefore, through combustion. ROS exist in the gas of cigarette smoke or are attached to suspended particulate; only a few remain in the tobacco ash. We conclude that the ROS in cigarette smoke arise mainly from combustion.

ROS elimination rates through the use of cigarette filters

From the results of our experiments with the cigarette brands chosen, we found no apparent change in ROS 


\section{Huang et al.}

concentrations, with or without filters. The only possible function of the filter was the absorption or separation of very small amounts of particulate or gaseous ROS by the filter foam. The ROS elimination rate when using filters was extremely small, with charcoal filters showing little improvement in efficacy over regular filters. In other words, ROS generated by cigarette combustion is drawn into smokers' lungs, the difference between filtered and unfiltered cigarettes being negligible. This conclusion illustrates the importance of further investigation into ROS in tobacco smoke.

\section{References}

Bartold, P.M., Wiebkin, O.W. and Thonard, J.C. (1984) The effect of oxygen-derived free radicals on gingival xproteoglycans and hyaluronic acid, J. Periodontal Res., 19, 390-400.

Church, D.F. and Pryor, W.A. (1985) Freeradical chemistry of cigarette smoke and its toxicological implications, Environ. Health Persp., 64, 111-126.

Cosgrove, J.P., Borish, E.T., Church, D.F. and Pryor, W.A. (1985) The metal-mediated formation of hydroxyl radical by aqueous extracts of cigarette tar, Biochem. Biophys. Res. Commun., 132, 390-396.

Halliwell, B., Gutteridge, J.M. and Cross, C.E. (1992) Free radicals, antioxidants, and human disease: where are we now? J. Lab. Clin. Med., 119, 598-620.

Hung, H.F. and Wang, C.S. (2001) Experimental determination of reactive oxygen species in Taipei aerosols, J. Aerosol. Sci., 32, 1201-1211.
Kao, M.C. (2001) A Study of Reactive Oxygen Species Generated from Incense Burning, Master's thesis, National Taiwan University, Public Health College, Environmental Health Institute.

Kensler, W. and Trush, M.A. (1984) Role of oxygen radicals in tumor promotion, Environ. Mutag., 6, 593-616.

Kilgore, K.S. and Lucchesi, B.R. (1993) Reperfusion injury after myocardial infarction: the role of free radicals and the inflammatory response, Clin. Biochem., 26, 359-370.

Pryor, W.A. and Stone, K. (1993) Oxidants in cigarette smoke. Radicals, hydrogen peroxide, peroxynitrate and peroxynitrite, Ann. N. Y. Acad. Sci., 686, 12-27.

Pryor, W.A., Prier, D.G. and Church, D.F. (1983) Electron-spin resonance study of mainstream and sidestream cigarette smoke: nature of the free radicals in gasphase smoke and in cigarette tar, Environ. Health Persp., 47, 345-355.
Pryor, W.A., Stone, K., Zang, L.Y. and Bermudez, E. (1998) Fractionation of aqueous cigarette tar extracts: fractions that contain the tar radical cause DNA damage, Chem. Res. Toxicol., 11, 441448.

Salim, A.S. (1993) Scavengers of oxygen-derived free radicals prolong survival in advanced colonic cancer. A new approach, Tumor Bio., 14, 9-17.

Uzel, N., Sivas, A., Uysal, M. and Oz, H. (1987) Erythrocyte lipid peroxidation and glutathione peroxidase activities in patients with diabetes mellitus, Horm. Metab. Res., 19, 89-90.

Yildiz, D., Liu, Y.S., Ercal, N. and Armstrong, D.W. (1999) Comparison of pure nicotine- and smokeless tobacco extractinduced toxicities and oxidative stress, Arch. Environ. Contam. Toxicol., 37, 434439. 